UCRL-JC-113839

PREPRINT

The New LLNL AMS Sample Changer

M.L. Roberts, P.J. Norman, J.L. Garibaldi, and R.S. Hornady

This paper was prepared for submittal to 6th International Conference on Accelerator Mass Spectrometry

Canberra-Sydney, Australia

September 27 - October 1, 1993

September 7, 1993

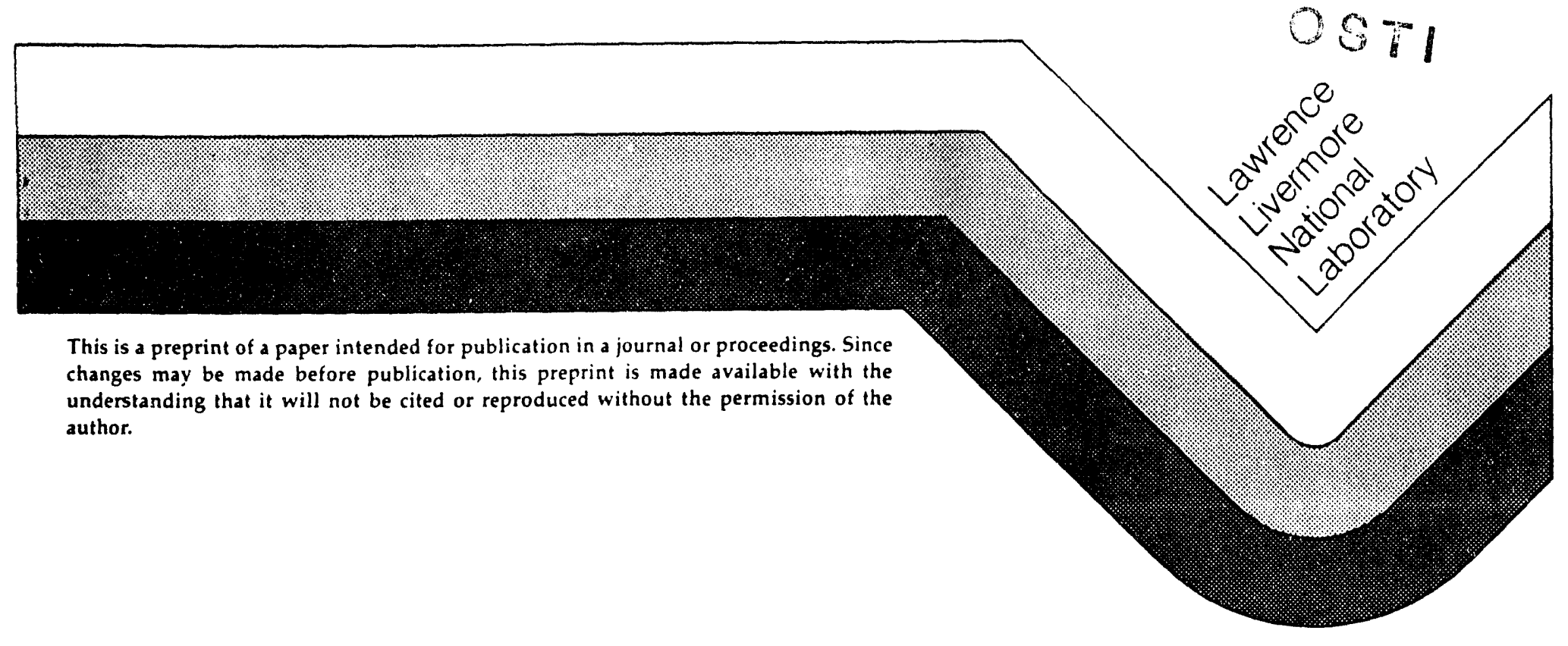




\section{DISCLAIMER}

This document was prepared as an account of work sponsored by an agency of the United States Government. Neither the United States Government nor the University of California nor any of their employees, makes any warranty, express or implied, or assumes any legal liability or responsibility for the accuracy, completeness, or usefulness of any information, apparatus, product, or process disclosed, or represents that its use would not infringe privately owned rights. Reference herein to any specific commercial products, process, or service by trade name, trademark, manufacturer, or otherwise, does not necessarily constitute or imply its endorsement, recommendation, or favoring by the United States Government or the University of California. The views and opinions of authors expressed herein do not necessarily state or reflect those of the United States Government or the University of Califomia, and shall not be used for advertising or product endorsement purposes. 


\title{
The New LLNL AMS Sample Changer
}

\author{
M.L. Roberts, P.J. Norman, J.L. Garibaldi, and R.S. Hornady \\ Center for Accelerator Mass Spectrometry \\ Lawrence Livermore National Laboratory \\ Livermore, CA 94551 USA
}

\begin{abstract}
The Center for Accelerator Mass Spectrometry at LLNL has installed a new 64 position AMS sariple changer on our spectrometer. This new sample changer has the capability of being controlled manually by an operator or automatically by the AMS data acquisitinn computer. Automatic control of the sample changer by the data acquisition system is a necessary step towards unattended AMS operation in our laboratory. The sample changer uses a fiber optic shaft encoder for rough rotational indexing of the sample wheel and a series of sequenced pneumatic cylinders for final mechanical indexing of the wheel and insertion and retraction of samples. Transit time from sample to sample varies from $4 \mathrm{~s}$ to $19 \mathrm{~s}$, depending on distance moved. Final sample location can be set to within 50 microns on the $x$ and $y$ axis and within 100 microns in the $z$ axis. Changing sample wheels on the new sample changer is also easier and faster than was possible on our previous sample changer and does not require the use of any tools.
\end{abstract}

This work performed under the auspices of the U.S. Department of Energy at the Lawrence Livermore National Labnratory under contract W-7405-Eng-48. 


\section{Introduction}

Lawrence Livermore National Laboratory (LLNL) operates a high throughput, moderate precision AMS facility. One of the long-standing goals for our facility has been the ability to collect AMS data in an automated, unattended manner. Unattended AMS operation for 'routine' samples will decrease scheduling difficulties and potentially increase our measurement throughput. As a necessary (but not sufficient) step towards unattended AMS operation, we have built and installed a new AMS sample changer. This new changer has 64 sample positions with the option of being controlled automatically by our data acquisition computer or manually by an operator.

The new LLNL sample changer is coupled directly to our heavily modified Genus Model 846 sputter source. Experience with this particular ion source has been reported on previously[1] and will not be discussed here. This paper will discuss only the sample changer mechanism.

\section{The Previous Sample Changer}

Our previous sample changer had at least one good characteristic and several undesirable characteristics. The one crood characteristic that our original sample changer had (and as has been reported previously[1]), was that there were no fragile and/or active electronic components at cathode potential. Positioning and insertion of samples was accomplished using a small air turbine motor and several pneumatic air cylinders controlled by air solenoid valves located at ground. Unfortunately, however, proper sequencing of these solenoids was effected by an operator pushing several switches in succession while observing a remote television screen and listening for the appropriate audio responses. No position information or sequence completion indication was returned to ground or the data acquisition computer. Although this system served us well for almost three years, it would have been difficult to retrofit or modify our old sample changer in order to implement computer control.

A second undesirable characteristic of the old sample changer was that the physical act of changing its 60 position sample wheel was fairly difficult. To change a sample wheel it was necessary to climb a short stepladder, place one's body in a rather awkward position and remove several screws and 
shoulder bolts with each screw naturally requiring a different hand tool. It frequently took longer than an hour to load a new sample wheel and restart the data acquisition process. Since it only takes 3 hours to measure some of our 60 sample biomedical ${ }^{14} \mathrm{C}$ AMS wheels, spending an hour to change sample wheels was not acceptable in terms of productivity and sample throughput.

A third undesirable characteristic of the original sample changer was that it was constructed largely of aluminum. The poor vacuum characteristics of aluminum were of concern to several of our group members as a possible source of memory effects. While no sample memory effects were ever directly attributed to the sample changer, many in our group desired a new sample changer constructed out of stainless steel as much as practicable.

\section{The New Sample Changer}

After deciding what we did and did not want in a sample changer, we designed and constructed a new AMS sample changer. A picture of the new LLNL AMS sample changer is shown in Figure 1. The sample changer is controllable by the AMS data acquisition computer, has no fragile electronic components at cathode potential, is fabricated from stainless steel as much as was feasible, and is designed to make changing sample wheels fast and easy.

Compared to the old sample changer, changing sample wheels on the new sample changer is easy. To change sample wheels, an operator merely closes the appropriate hand valve, back fills the sample changer housing with Argon, removes three large thumbscrews, and replaces the old sample wheel with a new one. Also, this entire procedure can be accomplished with the operator standing at ground level. Changing sample wheels and restarting data acquisition can now be done in less than 20 minutes.

For unattended AMS operation, the new AMS sample changer can be controlled by the AMS data acquisition system. To initiate a sample change, the AMS data acquisition system ${ }^{[2]}$ writes the requested sample position to a Kinetic Systems Corporation Model 3072 output register. This request is then relayed through a pair of LONWorks TP/XF-78 twisted pair control modules to a grounded 


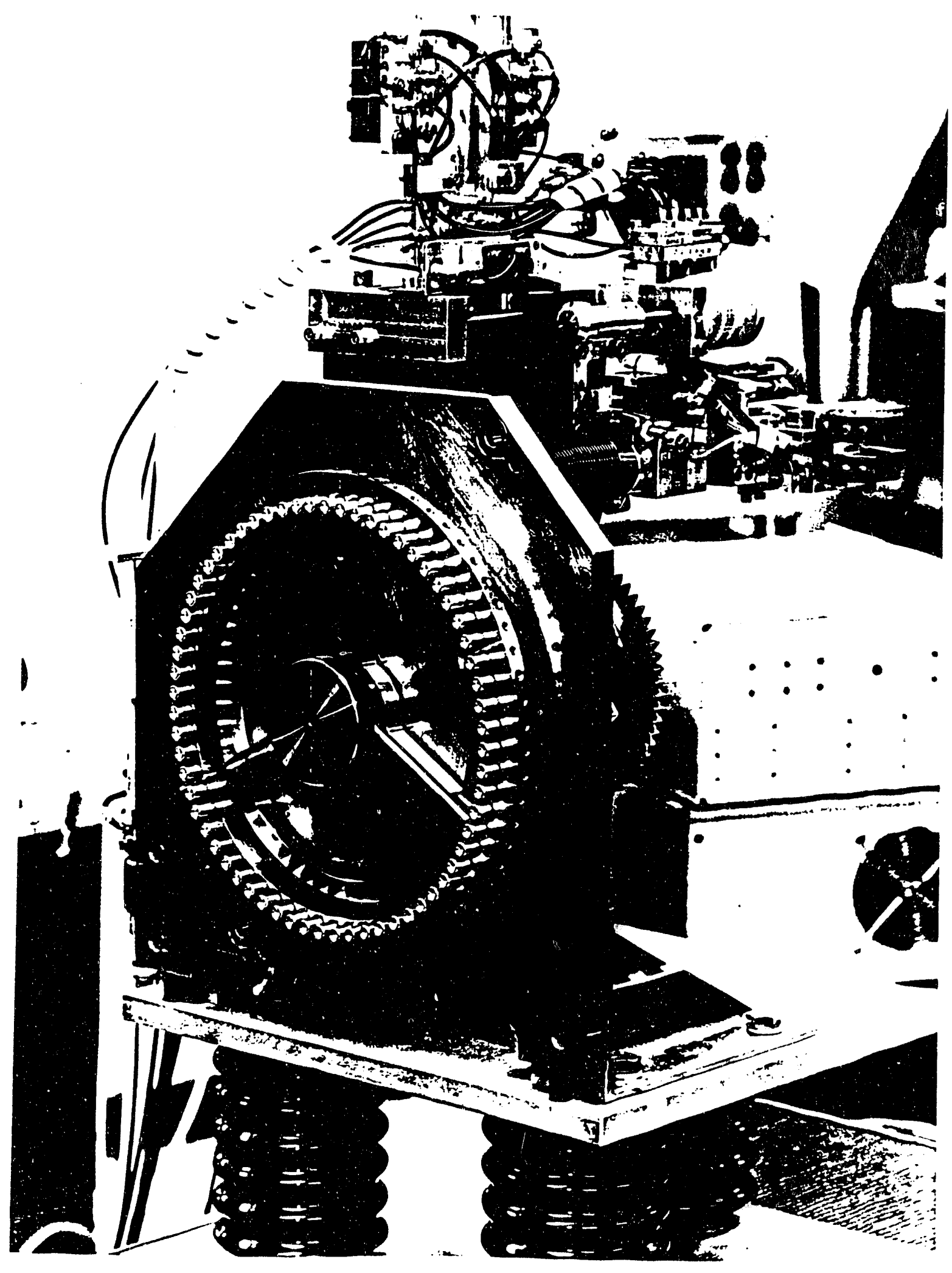

Figure 1. The new LLNL AMS sample changer. 
control rack located next to the AMS ion source/sample changer. Electronics in this grounded control rack responds to a change in position request and appropriately activates/deactivates the sample insertion solenoid and sample wheel rotation solenoid. A detailed description of this twisted pair transceiver scheme and associated control electronics can be found elsewhere[3].

Rotation of the sample wheel is done at ion source cathode potential using an air turbine. The sample wheel is connected to the air turbine through a reducing drive and short chain. To minimize transit time from sample position to sample position, the air turbine can be driven in either direction. Rough rotational position of the sample wheel is determined by a fiber optic shaft encoder while final rotational indexing of the wheel is accomplished with an air actuated cam. The target wheel was intentionally made with sixty-four positions to match the binary output of the fiber optic encoder. In the particular fiber optic shaft encoder that we use, light is sent to the sensor head along one set of fibers and position information is received back on another set of fibers so that there are no active electronics at high voltage.

Insertion/retraction of a sample into the ion source is accomplished using several sequenced pneumatic cylinders. Proper sequencing and interlocking of these pneumatic cylinders is done using several miniature air valves and air operated flip-flops. A schematic of the air logic is shown in Figure 2. Typical transit time from the start of retraction of one sample to completion of insertion of another has been measured and varies from $4 \mathrm{~s}$ for a nearest neighbor move to $19 \mathrm{~s}$ for a furthest neighbor move. Once inserted into the ion source, samples are held in place using a spring loaded collet. This collet provides electrical contact, thermal contact, and positioning alignment between the sample and ion source. Final sample location can be set to within 50 microns on the $x$ and $y$ axis and within 100 microns in the $z$ axis.

\section{Summary}

The Center for Accelerator Mass Spectrometry at LLNL has built a new 64 position AMS sample changer. This new sample changer has the capability 


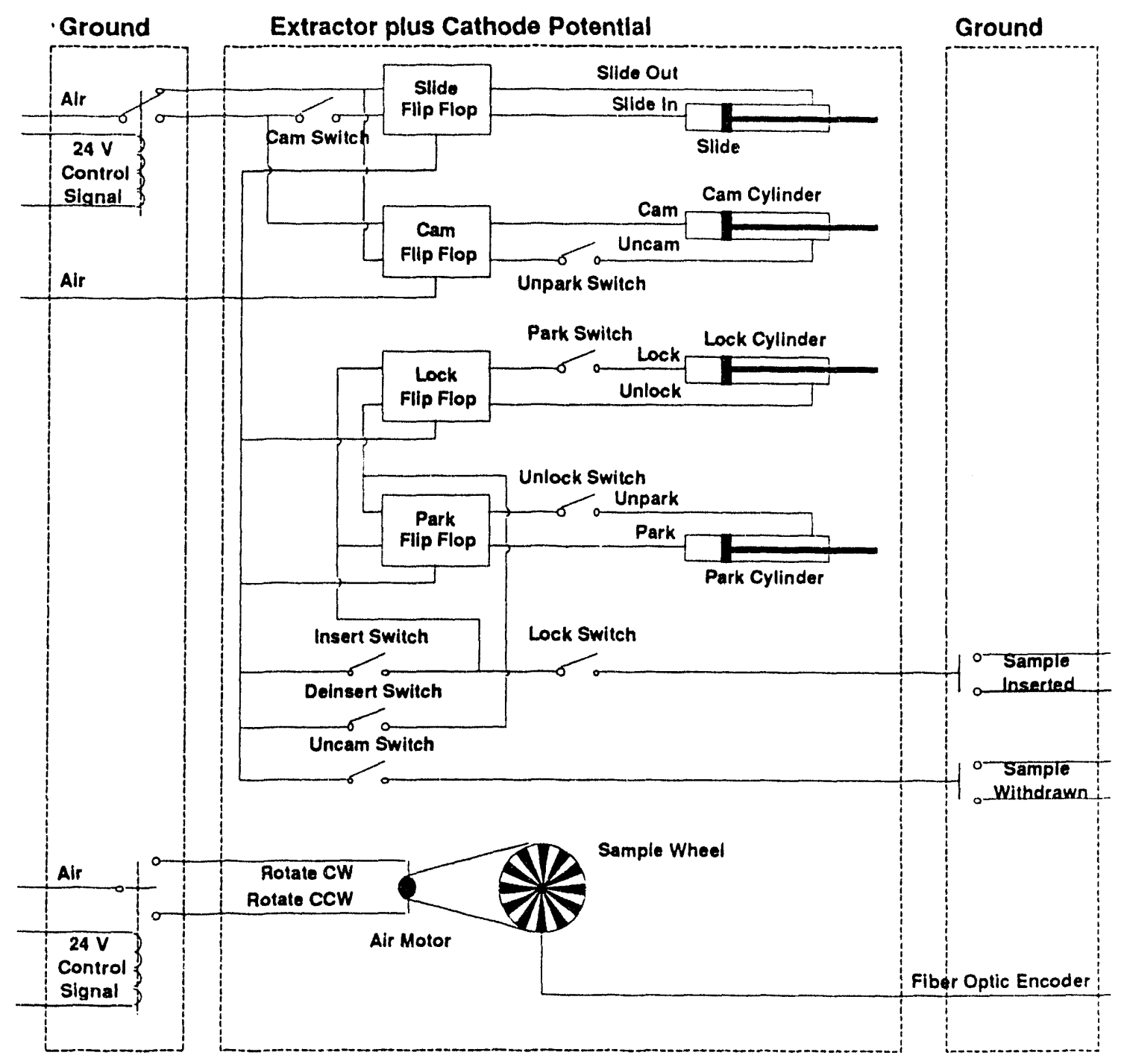

Figure 2. Air logic located at cathode potential.

of being controlled manually by an operator or automatically by the AMS data acquisition computer. To date, the new sample changer has worked reliably and been virtually maintenance free. Changing sample wheels on the new sample changer is also easier and faster than was possible on the previous sample changer. After approximately $61 / 2$ months of operation, some 9100 AMS samples (conservatively representing 40 to 50 thousand insertion/retraction cycles) have been measured using the new sample changer. Tests of computer control algorithms for unattended AMS operation have just begun. With the new sample changer and computer control algorithms now being tested, unattended AMS operation in our 
laboratory should soon become commonplace. This step has the potential to improve scheduling difficulties and increase our measurement throughput.

\section{References}

[1] I.D. Proctor, J.R. Southon, M.L. Roberts, J.C. Davis, D.W. Heikkinen, T.L. Moore, J.L. Garibaldi and A.T. Zimmerman, "The LLNL Ion Source - Past, Present, and Future", Nuclear Instruments and Methods in Physics Research B52 (1990) 334-337.

[2] A.J. Berno, J.S. Vogel and M.W. Caffee, "High Speed Acquisition of Multiparameter Data Using a Macintosh IIcx", Nuclear Instruments and Methods in Physics Research B56/57 (1991) 1076-1079.

[3] R.S. Hornady and G.L. Michalak, "The Development of a Distributed Remote Control System. A New Paradigm", Submitted to Review of Scientific Instruments. 

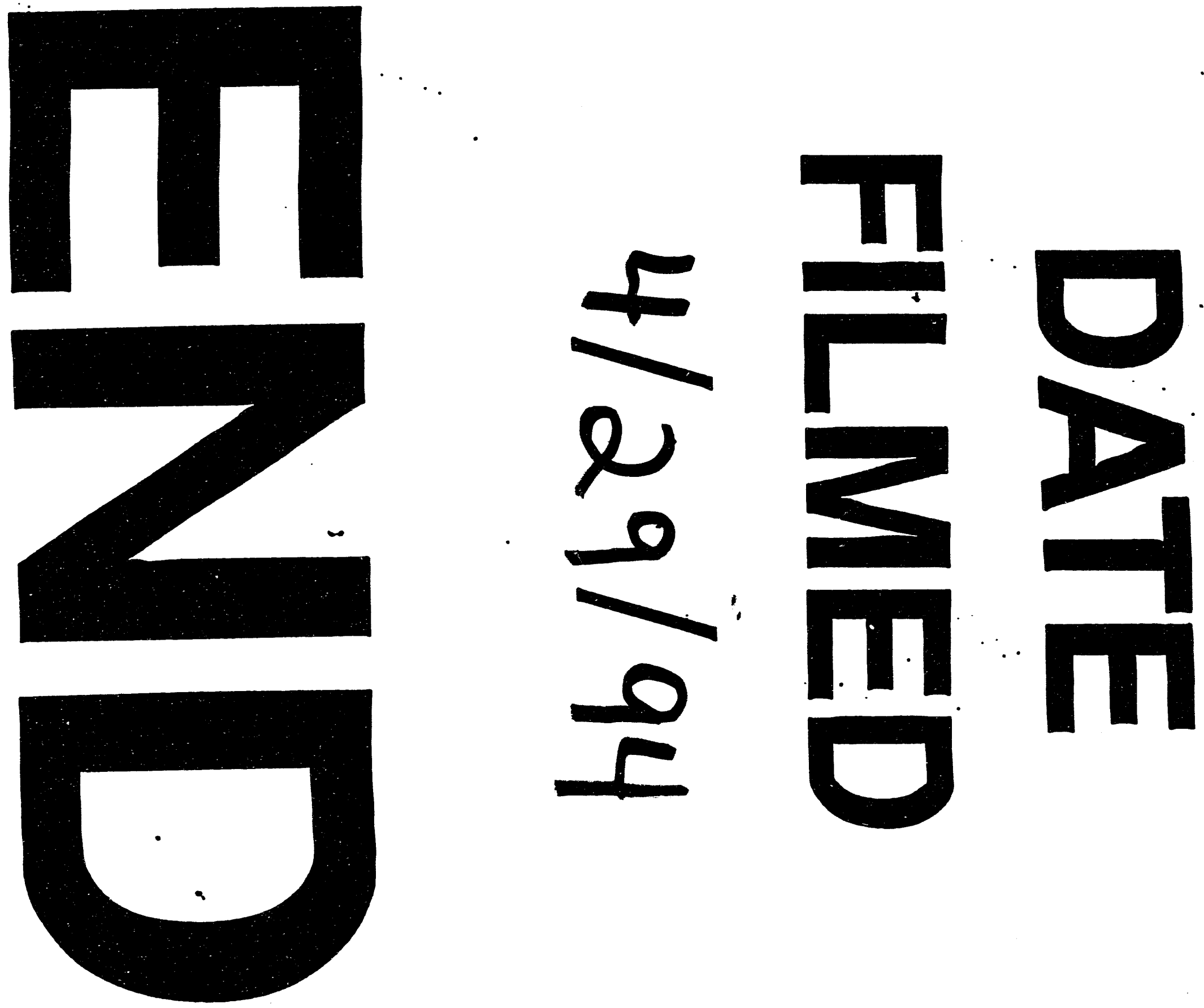
